\title{
CONDUCTOMETRIC DETERMINATION OF LOSARTAN POTASSIUM USING PHOSPHOTUNGSTIC ACID, BROMOCRESOL PURPLE, MERCURY (II) CHLORIDE, AND CUPRIC CHLORIDE AS REAGENTS
}

\author{
AFAF ABOUL-KHIER ABDEL-MONEM, EMAN AHMED BAHGAT*
}

Department of Analytical Chemistry, Faculty of Pharmacy, Zagazig University, Egypt. Email: eman_ahmad3332@yahoo.com

Received: 9 November 2018, Revised and Accepted: 21 December 2019

\section{ABSTRACT}

Objectives: In the current study a simple and precise four conductometric methods were introduced for determination of Losartan Potassium (LK) in pure form and tablets.

Methods: Method A is based on titration of LK using phosphotungstic acid, method B is based on titration of LK using bromocresol purple dye, method C is based on titration of LK using mercury (II) chloride, and method D is based on titration of LK using cupric chloride.

Results: LK was found to be linear in the concentration range of 3-20 mg/mL for all methods except for method C, the concentration range was 1-12 mg/mL. The obtained percentage recoveries for the four methods ranged from $99.69 \%$ to $100.53 \%$; the relative standard deviation values were not exceeding two for all methods.

Conclusion: The suggested methods were successfully applied for the determination of LK in tablets, with results in close agreement at $95 \%$ confidence level with those obtained using the reference spectrophotometric method.

Keywords: the determination of different compounds such as captopril

(C) 2020 The Authors. Published by Innovare Academic Sciences Pvt Ltd. This is an open access article under the CC BY license (http:/ / creativecommons.org/ licenses/ by/ 4.0/ ) DOI: http:/ / dx.doi.org/ 10.22159/ijms.2019.v7i1.30585

\section{INTRODUCTION}

Losartan potassium (LK) is an angiotensin II receptor antagonist with antihypertensive activity used in the treatment of hypertension [1]. Its chemical structure is 2-Butyl-4-chloro-1-[p-(o-1H-tetrazol-5-ylphenyl) benzyl] imidazole-5-methanol potassium [2] as shown in scheme 1.

There are various reported spectrophotometric methods for the analysis of losartan including ultraviolet (UV) spectrophotometry [3] reaction with bromothymol blue [4], bromophenol blue [5], and charge transfer complex formation with iodine, tetracyanoquinodimethane, p-chloranilic acid, and 2,4,7-trinitro-9-fluorenone [6]. Furthermore, fluorescence spectroscopic method has been reported for the determination of LK [7]. Furthermore, different chromatographic methods such as HPLC with UV detection [8,9], mass detection [10], thin-layer chromatography [11], and capillary electrophoresis [12] have been published for determination of LK. Electrochemical methods have also been reported including conductometric methods $[13,14]$ and potentiometric method [15]

The use of phosphotungstic acid (PTA), bromocresol purple (BCP) dye, mercury (II) chloride $\left(\mathrm{HgCl}_{2}\right)$, and cupric chloride $\left(\mathrm{CuCl}_{2}\right)$ in conductometric methods introduces several advantages over spectrophotometric ones, being easier, faster, and simpler. The methodsdetermine the cited drug without previous filtration or extraction and therefore avoiding organic solvents using.

Precipitimetry conductometric titrationsusingPTAas titrantre commonly used for the quantitative determination of different compounds such as reproterol $\mathrm{HCl}$, salbutamol sulfate [16], papaverine hydrochloride [17], and dextromethorphan [18]. PTA was also used in the spectrophotometric estimation of Mebikar [19].

Precipitimetry conductometric titrations using BCP dye as a titrant are not commonly used. It has been used for the determination of fexofenadine hydrochloride [20] and candesartan [21]. Furthermore, precipitimetric conductometric titrations using $\mathrm{HgCl}_{2}$ as a titrant are commonly used for the determination of different compounds, especially containing thiol groups such as 1-propanethiol, 2-propanethiol and 2-methyl 2-propanethiol [22]. Furthermore, precipitimetric conductometric titrations using $\mathrm{CuCl}_{2}$ as a titrant are commonly used for the determination of different compounds such as captopril [23] and gabapentin [24]

This paper introduces conductometric determination of LK using four reagents: PTA (method A), BCP dye (method B), $\mathrm{HgCl}_{2}$ (method $\mathrm{C}$ ), and $\mathrm{CuCl}_{2}$ (method D). The proposed methods are simple, practical, and reproducible and can be easily applied to determine LK in tablets.

\section{METHODS}

Materials and reagents

All reagents and chemical used were of analytical grade together with bidistilled water

- LK was kindly provided from Egyptian Int. Pharmaceutical Industries Co. (10 ${ }^{\text {th }}$ of Ramadan city, Egypt).

- $\quad$ PTA (PARK Scientific limited, Northampton, UK) $1 \times 10^{-3} \mathrm{M}$ prepared by dissolving $0.288 \mathrm{~g}$ in $100 \mathrm{ml}$ bidistilled water.

- $\quad$ BCP dye (Sigma Chem. Company, Milwaukee, USA) $5 \times 10^{-3} \mathrm{M}$ prepared by dissolving $0.27 \mathrm{~g}$ in the least amount of methanol then completing to $100 \mathrm{ml}$ with bidistilled water.

- $\mathrm{HgCl}_{2}$ (Universal Fine Chemicals PVT-LTD) stock solution of concentration $1 \times 10^{-2} \mathrm{M}$ prepared by dissolving 0.2715 Gin $100 \mathrm{ml}$ with bidistilled water. Working solution of a concentration of $5 \times 10$ ${ }^{4} \mathrm{M}$ was prepared by further dilution of the stock solution.

- $\mathrm{CuCl}_{2}$ (Aldrich Chemical Co. Ltd.) was prepared as $1 \times 10^{-3} \mathrm{M}$ solution by dissolving $0.0171 \mathrm{~g}$ in $100 \mathrm{ml}$ bidistilled water.

Pharmaceutical preparation

Losartan ${ }^{\circledR}$ tablets (Amriya Pharmaceutical Industries, Alexandria, Egypt) labeled to contain $50 \mathrm{mg}$ LK per tablet.

\section{Instrumentation}

JENWAY model 470 Conductivity/TDS Meter (470 201), with Conductivity/Temperature Probe (027 298) was used. 


\section{General procedures}

Preparation of stock and standard working solutions

LK standard solution of $1 \mathrm{mg} / \mathrm{ml}\left(2.17 \times 10^{-3} \mathrm{M}\right)$ was prepared by dissolving $100 \mathrm{mg}$ of the pure drug in bidistilled water then completing to $100 \mathrm{ml}$ with bidistilled water.

\section{Construction of calibration curves}

Aliquots of drug solution containing(3-20 mg),(3-20 mg), (1-12 mg), and (3-20 mg) for methods A, B, C, and D, respectively, were transferred to a $50 \mathrm{ml}$ calibrated flask; dissolved and completed to volume with bidistilled water. The contents of the calibrated flask were transferred to a beaker, and the conductivity cell was immersed.

PTA, BCP, $\mathrm{HgCl}_{2}$, and $\mathrm{CuCl}_{2}$ were used as titrant; the conductance was measured subsequent to each reagent solution addition after stirring for $1 \mathrm{~min}$, the conductance was corrected for dilution [25] by means of the following equation, assuming that conductivity is a linear function of dilution.

$$
\Omega^{-1} \text { correct }=\Omega^{-1} \text { obs }[(\mathrm{v} 1+\mathrm{v} 2) / \mathrm{v} 1]
$$

Where $\Omega^{-1}$ correct is the corrected electrolytic conductivity, $\Omega^{-1}$ obs is the observed electrolytic conductivity, v1 is the initial volume, and $\mathrm{v} 2$ is the volume of reagent added. A graph of corrected conductivity versus the volume of added titrant was constructed and end-point was detected.

The amount of drugs under study was calculated according to the following equation:

Amount of drug $=\mathrm{VMR} / \mathrm{N}$

Where $\mathrm{V}$ is the volume of titrant, $\mathrm{M}$ is molecular weight of drug, $\mathrm{R}$ is molar concentration of titrant, and $\mathrm{N}$ is no of moles of titrant consumed by 1 mole of drug.

Procedures for determination of stoichiometric ratio using Job's method [26]

About $6 \mathrm{~m}$ of $10^{-3} \mathrm{M}$ LK were transferred to $50 \mathrm{~mL}$ volumetric flasks and completed to volume with bidistilled water. The contents were transferred to a beaker and the conductivity cell was immersed. $10^{-3} \mathrm{M}$ PTA, BCP, $\mathrm{HgCl}_{2}$, and $\mathrm{CuCl}_{2}$ were used for titration. The conductance was measured subsequent to each reagent solution addition after thorough stirring for $1 \mathrm{~min}$. A graph of conductivity versus volume was constructed.

\section{Procedure for Losartan ${ }^{\circledR}$ tablets}

The contents of 10 tablets were pulverized, an accurately weighed amount equivalent to $100 \mathrm{mg}$ of the studied drug was extracted by shaking with $50 \mathrm{ml}$ bidistilled water in a $100 \mathrm{ml}$ volumetric flask, completed to mark using bidistilled water then filtered.

\section{RESULTS AND DISCUSSION}

\section{PTA method}

On using PTA as a titrant for the determination of LK, ion associate is formed leading to a regular rise in conductance up to the equivalence point where a sudden change in the slope occurs; a precipitate is formed

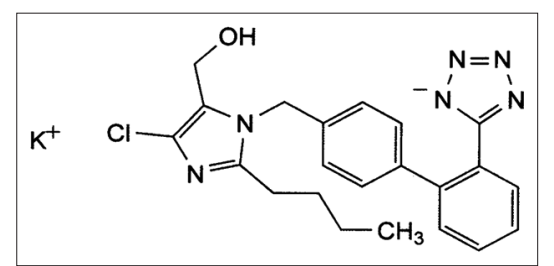

Scheme 1: Chemical structure of Losartan K through replacing $\mathrm{K}+$ by $\mathrm{H}+$ ion quantitatively forming insoluble losartan parent drug. The representative titration curve is shown in Fig. 1. Two straight lines are obtained, intersecting at the equivalence point. The first segment corresponds to the formed PTA potassium and the second segment represents the excess of PTA added.

The reaction may be represented by the following equations:

3 Losartan potassium $+\mathrm{H}_{3}$ PTALosartan +3 PTAPotassium $\rightarrow$ Parentdrug $\downarrow$

\section{BCP method}

On using BCP as a titrant for the determination of LK, ion associate is formed leading to a regular rise in conductance up to the equivalence point where a sudden change in the slope occurs, a precipitate is formed through replacing $\mathrm{K}^{+}$by $\mathrm{H}^{+}$ion quantitatively forming insoluble losartan parent drug. A representative titration curve is shown in Fig. 2. Two straight lines are obtained, intersecting at the equivalence point. The first segment corresponds to the formed BCP potassium and the second segment represents the excess of BCP added.

The reaction may be represented by the following equation:

1Losartan potassium +BCPIosartan+BCP potassium $\rightarrow$ Parent $\operatorname{drug} \downarrow$

\section{$\mathrm{HgCl}_{2}$ method}

On using $\mathrm{HgCl}_{2}$ as a titrant for the determination of $\mathrm{LK}$ a precipitate is formed through replacing $\mathrm{K}^{+}$by $\mathrm{Hg}^{+2}$ ion quantitatively forming insoluble mercuric salt with the drug. A representative titration curve is shown in Fig. 3. Two straight lines are obtained, intersecting at the equivalence point. The first segment corresponds to the formed potassium chloride and the second segment represents the excess of $\mathrm{HgCl}_{2}$ added.

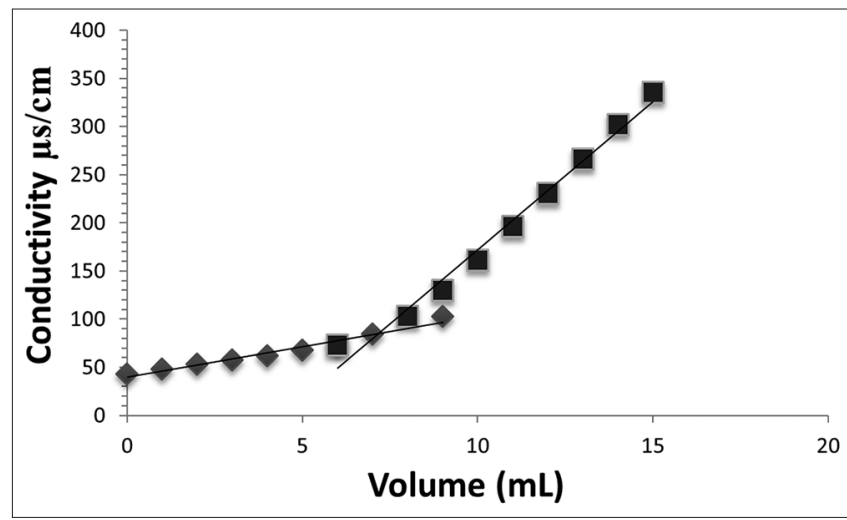

Fig. 1: Conductometric titration of $10 \mathrm{mg}$ of LK using $1 \times 10^{-3} \mathrm{M}$ PTA

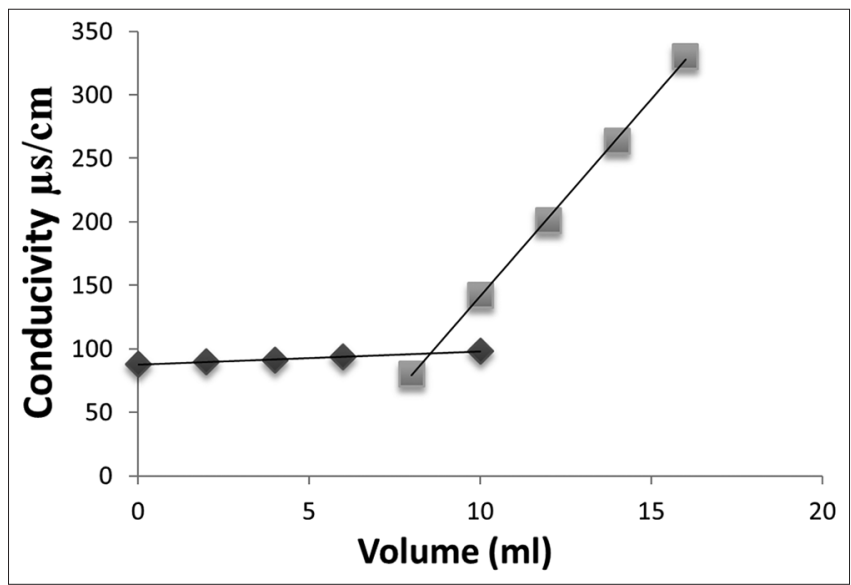

Fig. 2: Conductometric titration of $20 \mathrm{mg}$ of Losartan potassium using $5 \times 10^{-3} \mathrm{M}$ bromocresol purple dye 
The reaction may be represented by the following equation:

2 Losartan potassium $+\mathrm{CuCl}_{2}$ Losartan cupper $+\rightarrow 2 \mathrm{KCl} \downarrow$

$\mathrm{CuCl}_{2}$ method

On using $\mathrm{CuCl}_{2}$ as a titrant for the determination of LK a precipitate is formed through replacing $\mathrm{K}^{+}$by $\mathrm{Cu}^{+2}$ ion quantitatively forming insoluble cupric salt with the drug. A representative titration curve is shown in Fig. 4. Two straight lines are obtained, intersecting at the equivalence point. The first segment corresponds to the formed potassium chloride and the second segment represents the excess of $\mathrm{CuCl}_{2}$ added.

The reaction may be represented by the following equation:

2 Losartan potassium $+\mathrm{CuCl}_{2}$ Losartan cupper $\rightarrow+2 \mathrm{KCl} \downarrow$

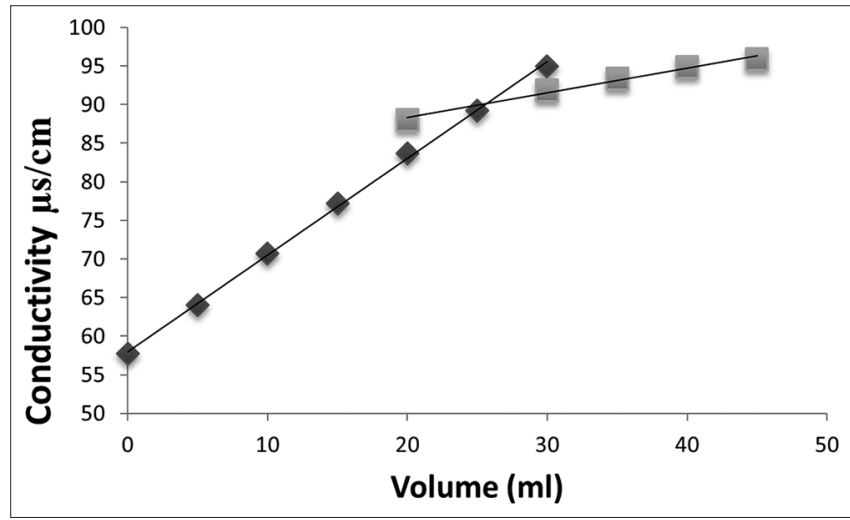

Fig. 3: Conductometric titration of $12 \mathrm{mg}$ of LK using $5 \times 10^{-4} \mathrm{M} \mathrm{HgCl}_{2}$

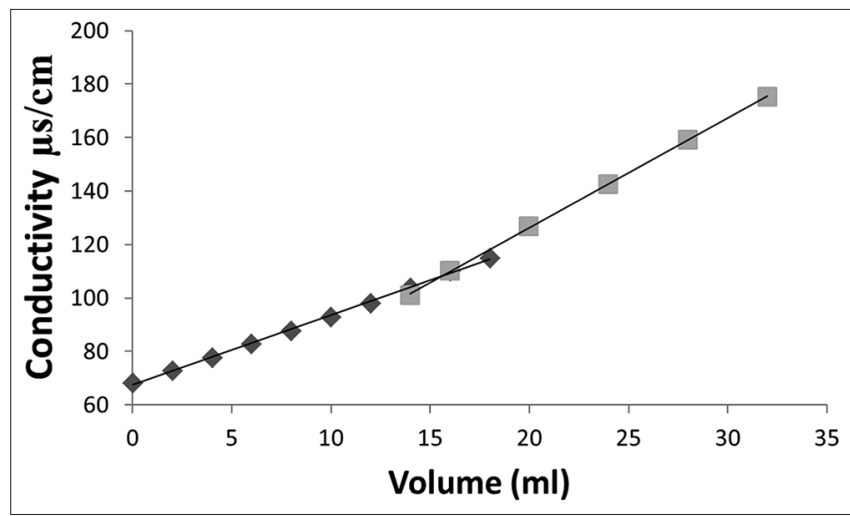

Fig. 4: Conductometric titration of $15 \mathrm{mg}$ of $\mathrm{LK}$ using $1 \times 10^{-3} \mathrm{M} \mathrm{CuCl}_{2}$
The results from the conductometric titrations are summarized in Table 1.

The data show that accurate results were obtained with good percentage recoveries and low standard deviation values. The optimum concentration ranges for the determination of LK were in the range of 1-20 $\mathrm{mg}$ for method C and 3-20 mg for methods A, Bm and Dm respectively. Stable conductance readings and sharp inflections were achieved at such ranges.

Investigations were carried out to establish the most favorable conditions for the reaction to reach the end point. The effects of some variables on the reaction have been examined, and the optimum conditions for performing the titration in a quantitative manner were explained as described below.

Titrations in different media were tried to obtain the best results. Preliminary experiments in

1. Aqueous solutions of both drug and reagent,

2. Drug and reagent solutions in ethanol-water (50\%, v/v) mixture

3. Methanolic solutions of both drug and reagent,

4. Drug and reagent solutions in methanol-water $(50 \% \mathrm{v} / \mathrm{v})$ mixture,

5. Drug and reagent solution in acetone-water $(50 \% \mathrm{v} / \mathrm{v})$ mixture

Preliminary experiments showed that procedure in aqueous media was the most suitable for successful results for the cited drugs where the highest conductance and the sharpest endpoints were obtained.

\section{Reagent's concentration}

The optimum concentrations of PTA, BCP, $\mathrm{HgCl}_{2}$, and $\mathrm{CuCl}_{2}$ were $1 \times 10^{-3} \mathrm{M}, 5 \times 10^{-3} \mathrm{M}, 5 \times 10^{-4} \mathrm{M}$, and $1 \times 10^{-3} \mathrm{M}$, respectively, to achieve a constant and highly stable conductance reading after 1 min mixing. Concentrations less than these gave unstable readings and more time were needed to obtain constant conductance values.

\section{Determination of the drug-titrant ratio}

Curve break is observed at drug-reagent molar ratios of 3:1 and 1:1 for methods A and B, respectively, and 2:1 for methods C and D.

\section{Method validation}

Linearity range

The developed method was validated according to the ICH guidelines [27]. The linearity range of conductivity as a function of drug concentration (Table 1) provides an accurate measure of the sensitivity of reagents used. Calibration curves have determination coefficients $\left(R^{2}\right)>0.999$ indicating good linearity.

\section{Accuracy and precision}

The accuracy of the method was expressed as the mean recovery percentage (average of four replicates within Beer's law limits) while

Table 1: Conductometric determination of $\mathrm{LK}$ in its pure form using PTA, $\mathrm{BCP}, \mathrm{HgCl}_{2}$, and $\mathrm{CuCl}_{2}$

\begin{tabular}{|c|c|c|c|c|c|c|c|}
\hline \multicolumn{2}{|l|}{$\mathrm{CuCl}_{2}$ method } & \multicolumn{2}{|c|}{$\mathrm{HgCl}_{2}$ method } & \multicolumn{2}{|l|}{ BCP method } & \multicolumn{2}{|l|}{ PTA method } \\
\hline Found \%* & Taken (mg) & Found \%* & Taken (mg) & Found \%* & Taken (mg) & Found \%* & Taken (mg) \\
\hline 100 & 3 & 99.12 & 1 & 101.53 & 3 & 101.38 & 3 \\
\hline 99.57 & 5 & 101.54 & 3 & 99.12 & 5 & 99.58 & 5 \\
\hline 100.13 & 7 & 99.57 & 5 & 100.46 & 7 & 100.27 & 10 \\
\hline 99.58 & 10 & 98.81 & 7 & 101.38 & 10 & 99.12 & 12 \\
\hline 100.8 & 15 & 99.12 & 10 & 101.54 & 15 & 99.58 & 15 \\
\hline 101.43 & 20 & 100 & 12 & 99.12 & 20 & 99.58 & 20 \\
\hline $100.25 \pm 0.733$ & & $99.69 \pm 0.996$ & & $100.53 \pm 1.159$ & & $99.92 \pm 0.805$ & Mean \pm SD \\
\hline 6 & & 6 & & 6 & & 6 & $\mathrm{~N}$ \\
\hline 0.536 & & 0.991 & & 1.345 & & 0.648 & $\mathrm{~V}$ \\
\hline 0.299 & & 0.407 & & 0.474 & & 0.328 & S.E \\
\hline 0.731 & & 0.999 & & 1.153 & & 0.804 & R.S.D \\
\hline
\end{tabular}

*Average of three different experiments. RSD: Relative standard deviation, $\mathrm{BCP}$ : Bromocresol purple, $\mathrm{HgCl}_{2}$ : $\mathrm{Mercury}_{\text {(II) }}$ chloride, $\mathrm{CuCl}$ : $\mathrm{Cupric}$ chloride, PTA: Phosphotungstic acid, SE: Standard error, SD: Standard deviation, LK: Losartan potassium 
Table 2: Evaluation of the interday and intraday precisions and accuracy for LK obtained by the proposed methods

\begin{tabular}{|c|c|c|c|c|c|c|c|}
\hline \multirow[t]{2}{*}{ Method } & \multirow{2}{*}{$\begin{array}{l}\text { Taken } \\
\text { Conc. (mg) }\end{array}$} & \multicolumn{3}{|l|}{ Interday } & \multicolumn{3}{|l|}{ Intraday } \\
\hline & & Accuracy (Er \%) & Precision (RSD \%)* & Recovery (\%)* & Accuracy (Er \%) & Precision (RSD \%)* & Recovery (\%)* \\
\hline PTA & $5 \mathrm{mg}$ & 1.12 & 1.38 & 101.12 & 0.275 & 1.78 & 100.275 \\
\hline ВСР & $5 \mathrm{mg}$ & -0.42 & 0.757 & 99.58 & 0.274 & 0.88 & 100.274 \\
\hline $\mathrm{HgCl}_{2}$ & $3 \mathrm{mg}$ & 0.275 & 1.47 & 100.275 & 1.15 & 0.76 & 101.15 \\
\hline $\mathrm{CuCl}^{2}$ & $5 \mathrm{mg}$ & 1.42 & 1.48 & 101.42 & -1.35 & 1.87 & 98.65 \\
\hline
\end{tabular}

RSD\%: Relative standard deviation percentage, Er\%: Relative error percentage, *Mean of five determination, PTA: Phosphotungstic acid, BCP: Bromocresol purple, $\mathrm{HgCl}_{2}$ : Mercury (II) chloride, $\mathrm{CuCl}_{2}$ : Cupric chloride, LK: Losartan potassium

Table 3: Conductometric determination of $\mathrm{LK}$ in Losartan ${ }^{\circledR}$ tablets using PTA, $\mathrm{BCP}, \mathrm{HgCl}_{2}$, and $\mathrm{CuCl}_{2}$

\begin{tabular}{|c|c|c|c|c|c|c|c|}
\hline \multicolumn{2}{|c|}{$\mathrm{CuCl}_{2}$ method } & \multicolumn{2}{|l|}{$\mathrm{HgCl}_{2}$ method } & \multicolumn{2}{|l|}{ BCP method } & \multicolumn{2}{|l|}{ PTA method } \\
\hline Found \%* & Taken (mg) & Found \%* & Taken (mg) & Found \%* & Taken (mg) & Found \%* & Taken (mg) \\
\hline 99.69 & 3 & 101.43 & 2 & 100 & 3 & 99.58 & 5 \\
\hline 98.68 & 7 & 99.57 & 5 & 98.81 & 7 & 100.96 & 10 \\
\hline 101.42 & 10 & 101.45 & 7 & 99.08 & 10 & 100.23 & 12 \\
\hline 98.34 & 15 & 99.12 & 10 & 99.88 & 12 & 99.58 & 15 \\
\hline 99.88 & 20 & & & & & 100.96 & 20 \\
\hline $99.91 \pm 1.322$ & & $100.62 \pm 1.177$ & & $99.37 \pm 0.533$ & & $100.12 \pm 0.709$ & Mean $\pm S D$ \\
\hline 6 & & 5 & & 5 & & 6 & $\mathrm{~N}$ \\
\hline 1.748 & & 1.385 & & 0.284 & & 0.502 & V \\
\hline 0.539 & & 0.526 & & 0.239 & & 0.289 & S.E \\
\hline 1.323 & & 1.169 & & 0.537 & & 0.709 & R.S.D \\
\hline
\end{tabular}

BCP: Bromocresol purple, $\mathrm{HgCl}_{2}$ : Mercury (II) chloride, $\mathrm{CuCl}_{2}$ : Cupric chloride, PTA: Phosphotungstic acid, RSD: Relative standard deviation, SE: Standard error, SD: Standard deviation, LK: Losartan potassium

Table 4: Statistical analysis of results obtained by the proposed methods applied on Losartan ${ }^{\circledR}$ tablets compared with the reported method

\begin{tabular}{llllll}
\hline Parameters & Reported method [6] & PTA method & BCP method & $\mathbf{H g C l}_{2}$ method & $\mathbf{C u C l}_{2}$ method \\
\hline Mean recovery & 99.99 & 100.12 & 99.37 & 100.62 & 99.91 \\
SD & 0.974 & 0.709 & 0.533 & 1.177 & 1.322 \\
$\mathrm{~N}$ & 6 & 6 & 5 & 5 & 6 \\
Variance & 0.95 & 0.502 & 0.284 & 1.385 & 1.748 \\
Student-t & & $1.894(2.220)^{*}$ & $1.265(2.262)^{*}$ & $0.972(2.262)^{*}$ & $1.84(2.220)^{*}$ \\
F-test & & $3.345(5.19)^{*}$ & $1.458(5.19)^{*}$ & $0.119(5.05)^{*}$ \\
\hline
\end{tabular}

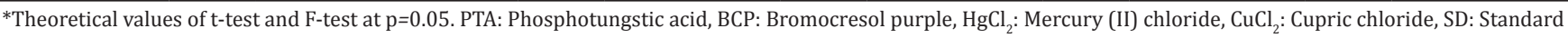
deviation

the precision was expressed as the relative standard deviation (RSD) percentage (Table 2).

\section{Analytical application}

The proposed method was successfully applied to the assay of the studied drug in its pharmaceutical formulations using the standard addition technique. Satisfactory results obtained for the recoveries of the drugs were in good agreement with the label claim and proved the suitability of the proposed methods (Table 3).

According to ICH guidelines, the obtained values indicated a high sensitivity of the proposed methods. Statistical comparison of the results obtained from the analysis of the studied drugs by the proposed method to those of reference method [6] using t-and F-tests, showed no significant difference between them (Table 4).

\section{CONCLUSION}

The suggested method has the advantages of simplicity and cost affectivity make it an alternative method to the more complex and expensive methods for assay of LK. The proposed method is easy and very useful for the determination of the studied drug in pharmaceutical formulations and can be applied in laboratories for routine analysis.

\section{REFERENCES}

1. Sweetman SC. Martindale-The Complete Drug Reference. $36^{\text {th }}$ ed. London: The Pharmaceutical Press; 2009.

2. Her Majesty's Stationery Office. The British Pharmacopoeia. Vol. 3. London, UK: Her Majesty's Stationery Office; 2013.

3. Subbarao J, Rao DP, Vidyadhara DS, Rao B, Sasidhar R. UV spectrophotometic validation for identification and determination of losartan potassium in tablets. Int J Pharm Tech 2012;4:4137-43.

4. Latheeshjlal L, Parthiban P, Alagarsamy V, Sunil M, Vaidhya MJ, Rama MT. Spectrophotometric determination of losartan potassium and itsdosage form by bromothymolblue and phosphate buffer. EJChem 2010; 7:320-4.

5. Ahmed S, Karajgi S, Simpi C, Savita S, Kalyane N. Visible spectrophotometricmethods for the estimation of Losartan potassium and omeprazole in single component pharmaceutical formulations. Inter J Pharm Tech Res2009;1:1247-50.

6. Darwish IA. Analyticalstudy for the charge-transfer complexes of losartan potassium. Anal Chim Acta 2005;549:212-20.

7. Amir F, Sahar K, Bakhshali M, Mehdi J. Determination of losartan potassium in the presence of hydrochlorothiazide via a combination of magneticsolid phase extraction and fluorometry techniques in urine samples. RSC Adv 2015;5:102895-903.

8. Rao K, Srinivas K. RP-HPLC method for the determination of losartan potassiumand ramipril incombined dosage form. IndianJPharm Sci2010; 72:108-11.

9. Hafez HM, Abdullah AE, Abdelaziz LM, Kamal MM. Quantitative 
determination of amlodipine besylate, losartan potassium, valsartan and atorvastatin calcium by HPLC in their pharmaceutical formulations. J Chromatogr Sep Techn 2014;5:1-5.

10. Shah H, Kundlik M, Patel N, Subbaiah G, Patel D, Suhagia B, et al. Rapiddetermination of losartan and losartanacid in human plasma by multiplexed LC-MS/MS. J Sep Sci 2009;32:3388-94.

11. Sathe S, Bari S. Simultaneous analysis of losartan potassium, atenolol, and hydrochlorothiazide in bulk and in tablets by high-performance thin-layer chromatography with UV absorption densitometry. Acta Chromatogr 2007; 19:270-8

12. Quaglia MG, Donati E, Carlucci G, Mazzeo P, Fanali S. Determination of losartan and hydrochlorothiazide in tablets by CE and CEC. J Pharm Biomed Anal 2002;29:981-7.

13. Magda A, Hisham A, Mervat H, Nagla K. Conductometric determination of certain pharmacological drugs using silver and bismuth. Int Res J Pharm Appl Sci 2013;3:140-8.

14. Rossini P, Felix F, Angnes L. A simple and precise conductometric method for the determination of losartan in pharmaceutical products. Cen Eur J Chem 2012;10:1842-9.

15. Ikram J, Jamel EB. Development of a new potentiometric modified carbon paste electrode for losartan potassium determination in pharmaceutical formulations. Anal Chem Indian J 2015;15:311-8.

16. Issa YM, Shoukry AF, El-Nashar RM. Conductimetric determination of reproterol $\mathrm{HCl}$ and pipazethate $\mathrm{HCl}$ and salbutamol sulphate in their pharmaceutical formulations. J Pharm Biomed Anal 2001;26:379-86.

17. El-Nashar RM, Rizk MS, Abdel-Ghani NT, Hamed SM. Flow-injection potentiometric and conductometric determination of papaverine hydrochloride in the parent substance and a related pharmaceutical preparation. Pharm Chem J 2007;41:447-54.
18. Khaled E, Hassan HA, Mohamed GG, Ragab FA, Seleim AA. Conductometric determination of dextromethorphan hydrobromide. Anal Chem 2011;10:134-40.

19. Kostebelov NV, Shormanov VK, Prokopov AA, Berlyand AS Spectrophotometric estimation of mebikar. Pharm Chem J 2000; 34:623-4.

20. Safwan A, Mouhammed K, Ruba M. Extractive spectrophotometric and conductometric methods fordetermination of fexofenadine hydrochloride in pharmaceutical dosage forms. Pharm Anal Acta 2013; S2:1-6.

21. Amin SA, Saleh HM, Ragah GH, Kamel IS. Sensitive spectrophotometric and conductometric methods for determination of candesartan using bromocresol green and bromocresol purple by ion pair complex formation. J Chem Mat Res 2015;2:42-8

22. Doane LM, Stock JT. Determination of thiols by conductometric titration withmercury (II) chloride in water and in N,N-dimethylformamide. Anal Chem 1978;50:1891-5.

23. Lourencao B, Marcolino-junior LH, Fatibello-filho O. Conductometric determination of captopril in pharmaceutical formulations usingcopper(II) sulphate as titrant. Quím Nova 2008;31:349-52.

24. Anis SM, Hosny MM, Abdellatef HE, El-Bolkiny MN. Spectroscopic and conductometric analysis of gabapentin. E J Chem 2011;8:1784-96.

25. Lingane JJ. Electroanalytical Chemistry. $2^{\text {nd }}$ ed. New York: Interscience; 1958. p. 90

26. Vosburg WC, Cooper GR. Complex Ions. I. The identification of complex ions in solution by spectrophotometric measurements. J Am Chem Soc 1941;63:437-42.

27. Guidance for Industry: Q2B of Analytical Procedures; Methodololgy: International Conference of Harmonization (ICH); 1996. 